ingly crystals of quartz, phenakite, tinstone, and byacinth (zircon), were placed in a tube and experimented on.

"The only crystals that gave definite results were tintone and hyacinth. A small crystal of the former mincral glowed with a finc yellow light, which was extinguished almost entirely when the long diagonal of the Nicol was perpendicular to the axis of the crystal.

"Here, thercfore, the plane of polarisation of the emitted light was parallel to the axis of the crystal, and here it is again the quicker, though in this case (of an optically positive crystal) it is the ordinary ray which corresponds to the light evoked by the electric stream.

"So far, then, the experiments accord with the quicker vibrations being called into play, and therefore in a negative crystal the extraordinary and in a positive crystal the ordinary is the ray cvoked.

"A crystal of hyacinth, however, introduced a new phenomenon. In this optically positive crystal the ordinary ray was of a pale pink hue, the extraordinary of a very beautiful lavender-blue colour. In another crystal, like the former from Expailly, the ordinary ray was of a pale bluc, the extraordinary of a deep violet. A large crystal from Ceylon gave the ordinary ray of a yellow colour, the extraordinary ray of a deep violet huc.

"Several other substances rere experimented on, including some that are remarkable for optical properties, among which were tourmaline, andalusite, enstatite, minerals of the augite class, apatite, topaz, chrysoberyl, peridot, garnets of various kinds, and parisite. So far, however, these minerals have given no result, and it will be seen that the crystals which have thus far given out light in any remarkable degrec are, besides diamond, uniaxal crystals (an anomaly not likely to be sustained by further experiment); and the only conclusion arrived at is, that the rays whose direction of vibration corresponds to the direction of maximum optical elasticity in the crystal are always originated where any light is given out. As yct, however, the induction on which so remarkable a principle is suggested cannot bc considered sufficiently extended to justify that principle being accepted as other than probablc."

WILLIAM CROOKES

\section{ON THE LAW OF FATIGUE IN THE WORK DONE BY MEN OR ANIHALS}

THF Rev. Dr. Ilaughton, of Trinity College, Dublin, has recently brought to a conclusion a scries of papers on Animal Mechanics published in the Procectings of the Royal Society. The ninth of these papers was appointed the Croonian Lecture for the present year, and the tenth paper closes the scries.

The most important subject involved in these papers is the experimental detcrmination of the law that regulates fatigue in men and animals, when work is done, so as to bring on fatigue.

Many writers, such as Bouguer, Euler, and others, have laid down mathematical formulax, connecting the force overcome with the velocity of the movement; but these theorctical speculations have never received the assent of practical engineers.

Venturoli points out a method of observations and experiments which would scrve to determine the form of the function which expresses the force in terms of the velocity, after which a few carcfully planned experiments would determine the constant coefficients; and he adds that "such a discovery would be of the greatest uscfulness to the science of mechanics, upon which it depends, how to employ, to the greatest possible advantage, the force of animal agents.",

Dr. Haughton believes that he has found the proper form of this function, by means of experiments, and sums it up in what he calls the Law of Faliguc, which he thus expresses :-
The product of the total work done by the rate of work is constant, at the time when fatigne stops the work.

If $W$ denote the total work done, the law of fatigue gives us-

or

$$
\begin{aligned}
W \frac{d W}{d t} & =\text { const. } \\
\frac{W^{2}}{T} & =\text { const. } .
\end{aligned}
$$

The experiments made by Dr. Haughton from 1875 to I 880 consisted chiefly in lifting or holding various weights by means of the arms; the law of fatigue giving, in each case, an appropriate equation, with which the results of the experiments were compared. When the experiments consisted in raising weights on the outstretched arms, at fixed rates, the law of fatigue gave the following expression-

$$
(w+a)^{2} n=A \text {. . . . . }
$$

where $w, n$, are the weight held in the hand, and the number of times it is lifted, $A$ is a constant to be determined by experiment, and $a$ another constant depending on the weight of the limb and its appendages.

The equation (2) represents a cubical hyperbola.

The useful work done is represented by the equation-

$$
w n=\frac{A w}{(w+a)^{2}} \cdot \text {. . . }
$$

This denotes a cuspidal cubic, and the usiful work is a maximum, when $i v=a$, or the weight used is equal to the constant depending on the weight of the limb and its appendages.

When the weights were lowered as well as raised at fixed rates, and no rest at all permitted, the law of fatigue became-

$$
\stackrel{n}{n} \frac{\left(\mathrm{I}+\beta^{0} \cdot t^{2}\right)}{t}=\Lambda \text {. . . . . }
$$

where $n, t$, are the number and time of lift, $A$ is a constant depending on experiment, and $\beta$ is a constant involving the time of lift $(\tau)$ at which the maximum work is done.

Equation (4) denotes a cuspidal cubic.

When the weights are held on the palms of the outstretched hands, until the experiment is stopped by fatigue, the law becomes-

$$
(w+a)^{2} t=A \text {. . . . . }
$$

where $t$ is the whole time of holding out.

This equation denotes a cubical hyperbola.

The Law of Fatigue seems, in itself, probable enough, but of course its real value depends on its agreement with the results of experiment.

If $W$ denote the total work donc and $R$ the rate of wor'k, the law becomes, simply-

$$
W \times R=\text { const. . . . . . }
$$

If different limbs, or animals were used, each working in its own way, and under its own conditions, the Law of Fatigue would become-

$$
W R=W_{1} R_{1}+W_{2} R_{2}+W_{3} R_{3}+\& \mathrm{c} .
$$

and the problem for the engincer would be, so to arrange the work and rate of work of each agent employed, as to make the useful zoork a maximum, the work both useful and not useful, in all its parts, remaining subject to the conditions imposed by equation (7).

In using equation (5) in his concluding paper, detailing the results of expcriments made on I)r. Alexander Macalister, Dr. Haughton treats $a$ as an unknown quantity, and finds from all the observations its most probable value to be-

$$
a=5.68 \text { Jbs. }
$$

This result was compared with that of direct measurements made on Dr. Macalister himself, and indirect measurements made on the dead subject, from all of which Dr. Haughton concluded the value of $a$ to bc-- 
$a=5.56$ lbs. \pm 0.125 (possible error).

This result agrees closely with that calculated from the law of fatigue.

It should be added that a proposal was made by Dr. Haughton to Dr. Macalister to make the experiment conclusive by direct amputation of his scapula, a course which he, unreasonably, objected to, as he draws the line of "vivisection" at frogs.

\section{A LACUSTRINE VOLCANO}

$\mathrm{TN}$ a recent number of $L a$ Nature further details, furnished by the French Consul of San Salvador, M. J. Laferrière, are given concerning the recent volcanic phenomenon in Lake Ilopango in that State. The accompanying illustration, from a photograph, will show the nature of the crater which has risen in the midst of the lake. Earthquakes were felt in San Salvador in the first half of January of this year; there were three strong shocks, less violent, however, than those of 1876 . These earthquakes had their centre in the vicinity of Lake Ilopango, in the midst of which rose three volcanic openings connected with each other. This new crater, which, seen from a distance as in the illustration, appears a small islet, rises above the surface of the water, however, about twenty metres. An attempt was made to approach it in a boat, but the waters were all in a state of ebullition from contact with the burning rock, and gave off torrents of steam. An abundant column of smoke rose in the air, assuming the aspect of an immense cloud, which was seen from a great distance, and formed an imposing spectacle. The phenomenon was preceded by an exceptional rising of the lake, increased by the abundant winter rains. According to an old tradition the

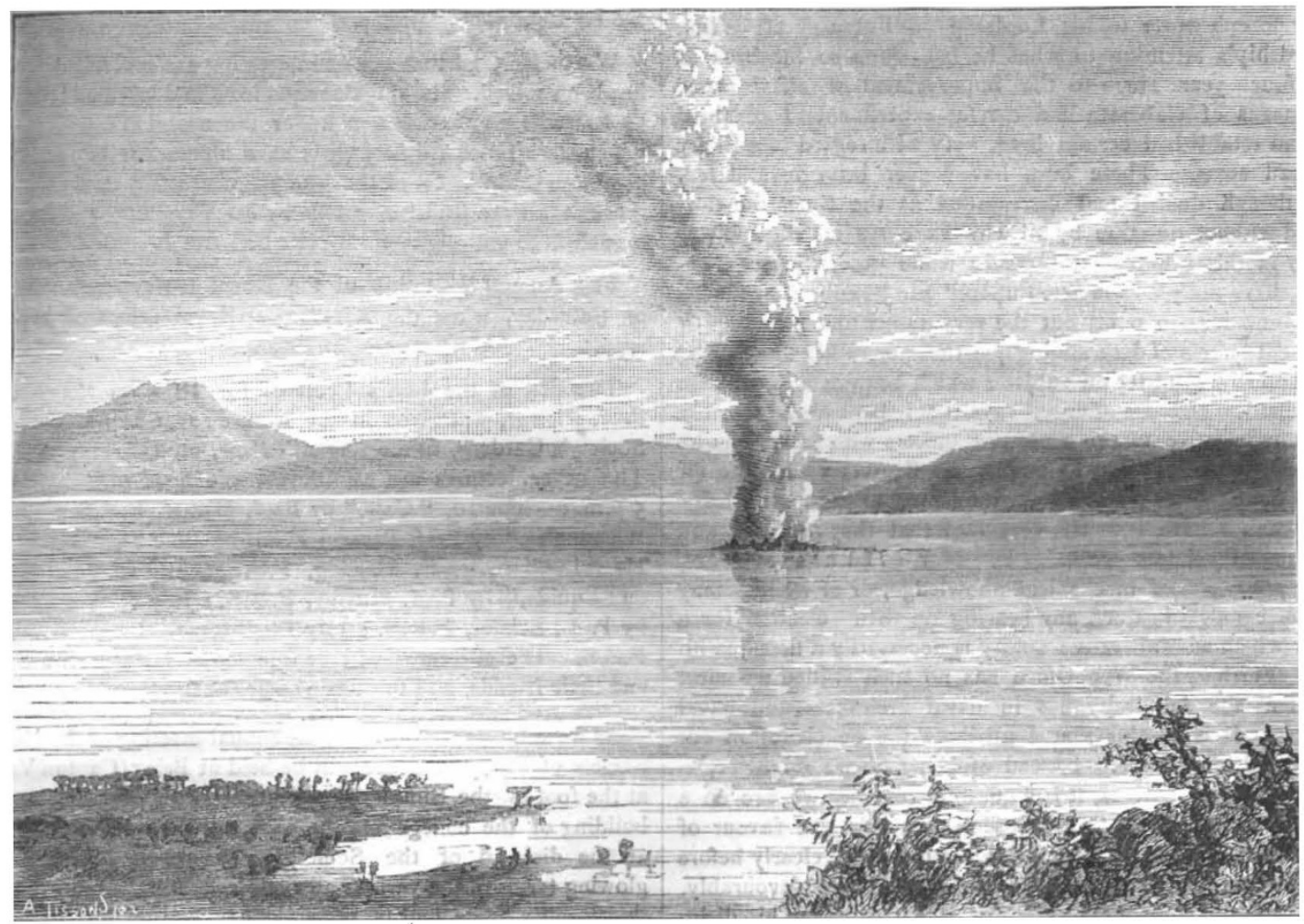

Aspect of the Volcano in Lake Ilopango. (From a Photograph.)

Spaniards maintain that when the lake rises earthquakes are to be feared. Formerly, also, it was the custom to dig trenches to facilitate the escape of the waters. This practice was followed without intermission for a century, and volcanic phenomena did not appear during all that time, The present phenomena seem to justify this tradition.

If it is difficult to explain the fact it is still interesting to remember that a great number of volcanoes are submarine, that others are found for the most part in islands or in maritime regions, and that water may be one of the feeders of volcanic fires. Lake Ilopango, also known as Lake Cojutepec, is, according to M. Laferrière, a sunk crater. It is in the volcanic line, and it is a general fact in Central America that lakes alternate with volcanic cones. The water of this lake is brackish, very bitter, and almost viscous. It gives off sometimes, here and there, bubbles of sulphohydric acid gas. The lake is about 12 kilometres long by 16 broad; the depth is unknown. It is about I2 kilometres from the city of San Salvador. The Consul of France in Guatemala, M. de Thiersant, states that Lake Ilopango has now a temperature of $38^{\circ} \mathrm{C}$. on its shore, and is in complete ebullition round the volcano. All the fishes are cooked and float upon the surface, with a great number of shellfish and other aquatic animals. The volcano continues to rise, and the level of the lake is being gradually lowered.

\section{NOTES}

THE candidates whose names we gave in a recent number (vol. xxi. p. 616) were elected Fellows of the Royal Society at the meeting of last Thursday. They are :-Dr. Clifford Allbutt, Prof. J. Attfield, Mr. H. E. Blanford, the Rev. W. H. Dallinger, Mr. Thiselton Dyer, Lieut.-Col. Godwin-Austen; the Bishop of Limerick, Prof. D. E. Hughes, Mr. H. M. Jeffery, 